Microporous and Mesoporous Materials 177 (2013) 97-104

DOI: 10.1016/j.micromeso.2013.04.024

\title{
Impact of silica structure of copper and iron-containing SBA-15 and SBA-16 materials on toluene oxidation
}

\author{
Ágnes Szegedi ${ }^{a}{ }^{*}$, Margarita Popova ${ }^{b}$, Károly Lázár $^{c}$, Szilvia Klébert ${ }^{a}$, and Eszter Drotár $^{a}$ \\ ${ }^{a}$ Institute of Materials and Environmental Chemistry, Research Centre for Natural Sciences, \\ Hungarian Academy of Sciences, 1025 Budapest, Pusztaszeri út 59-67, Hungary \\ ${ }^{b}$ Institute of Organic Chemistry with Centre of Phytochemistry, Bulgarian Academy of Sciences, \\ 1113 Sofia, Bulgaria \\ ${ }^{c}$ Centre for Energy Research, Hungarian Academy of Sciences, 1121 Budapest, Konkoly Thege \\ Miklós út 29-33, Hungary
}

\begin{abstract} stability in total oxidation of toluene.

Keywords: copper, iron, SBA-15, SBA-16, VOC oxidation

* corresponding author: Agnes Szegedi

e-mail: szegedi.agnes@ttk.mta.hu
\end{abstract}

Copper and iron modified SBA-15 and SBA-16 materials were prepared by incipient wetness impregnation technique and characterized by X-ray diffraction (XRD), transmission electron microscopy (TEM), $\mathrm{N}_{2}$ physisorption, temperature-programmed reduction (TPR-TGA), UV-Vis diffuse reflectance and Mössbauer spectroscopy. Formation of finely dispersed copper and ironoxide species was observed on both supports, whereas copper ferrite could be evidenced only on SBA-15. It was found that the structural and surface properties of the mesoporous supports determine the type of formed metal oxides, their dispersion, reducibility and the catalytic activity in total oxidation of toluene. On SBA-16 support penetration of metal salt into the bimodal channel system is hindered therefore separate copper- and iron-oxide phases are formed on the outer surface of catalysts. The catalytic activity and stability are lower due to the easier agglomeration of particles. On SBA-15 support finely dispersed metal-oxides can be found in the mesoporous channels. Their interaction is favored to form bimetallic phases enhancing the catalytic activity and

\section{INTRODUCTION}

During the last decades, mesoporous silica materials, with their uniform mesoporous channel structure and high specific surface area, have been of particular interest as catalyst supports [1-3]. Pore size and pore structure of the mesoporous silicas can significantly influence the formation of catalytically active phases. A wide variety of metal ions ( $\mathrm{Fe}, \mathrm{Ti}, \mathrm{V}, \mathrm{Cr}, \mathrm{Cu}, \mathrm{Mn}$ etc.) has been introduced into the silica matrix to obtain materials with tunable catalytic properties [4-15]. The high surface area and pore volume of the mesoporous supports allow high loadings of the active phase, and their large pore size makes the diffusion of the reactants easier, allowing enhanced availability of the catalytically active sites [16]. The catalytic properties of supported metal oxides strongly depend on the method of preparation, the type of salt precursors and supports used, which are all of crucial importance to obtain highly dispersed and active metal oxide species [3, 17-19]. The selection of an efficient support is of particular importance in order to obtain catalysts with 
good performance, because the state and structure of the support strongly influence the type of formed metal oxide species and their dispersion. The mesoporous SBA-15 and SBA-16 materials are synthesized in acidic media with different triblock copolymer surfactants. SBA-15 has the well known hexagonal structure, whereas the pore structure of SBA-16 consists of two noninterpenetrating three dimensional channel systems with spherical cavities at the dividing of the channels. It is expected that this unique structure offers more interesting opportunity for catalytic applications involving metal-support interactions [20, 21]. Until now cubic mesoporous SBA-16 system has not been studied so extensively as a support for catalytically active metal-oxide phase, like the hexagonal SBA-15.

The catalytic total oxidation is considered as the most appropriate method for the removal of volatile organic compounds (VOCs) [3, 17, 14, 22-27]. This process is of great importance because of the strict regulations on the environmental standards which require reduction of their emission. The design of a catalytic system for complete oxidation of hydrocarbons is an important problem of the environmental catalysis. Supported noble metals and metal oxides have been most intensively investigated for the combustion of volatile organic compounds (VOCs) [17, 23, 27]. The high price of noble metals and their sensitivity to high temperature and contamination has driven scientists to search for other types of suitable catalysts. Supported metal oxides $(\mathrm{Cu}, \mathrm{Co}$, $\mathrm{Fe}, \mathrm{Ni}, \mathrm{Mo}, \mathrm{V}$, etc.) are an alternative to the noble metals as catalysts for complete oxidation [22, 24-26]. Among them, copper supported catalysts are one of the most promising ones for VOC oxidation processes $[24,25]$. Their catalytic properties strongly depend on the oxidation state and the coordination of the copper ions. The nature and dispersion of copper oxide species in the silica matrix can be influenced by the peculiarities of the mesoporous structure and also by its modification with a second metal. $\mathrm{CuO} / \mathrm{Fe}_{2} \mathrm{O}_{3}$ catalysts have been studied for carbon monoxide oxidation [28], hydrogen production reactions [29], water-gas-shift reaction, peroxide decomposition reactions [30] and organic oxidation reactions [31]. It was found that $\mathrm{CuO} / \mathrm{Fe}_{2} \mathrm{O}_{3}$ supported on cordierite possess higher catalytic activity in comparison to the monocomponent ones. It was also found that the $\mathrm{Cu}$ :Fe ratio and specific surface area strongly influence the activity in $\mathrm{CO}$ oxidation. [32]. Litt et al. [33] found that mixed metal oxide $\left(\mathrm{CuO} / \mathrm{Fe}_{2} \mathrm{O}_{3}\right)$ catalysts are more active in total oxidation of ethanol than pure $\mathrm{CuO}$ or $\mathrm{Fe}_{2} \mathrm{O}_{3}$. This is probably due to the greater lattice oxygen mobility in the mixed oxide catalysts, essential step in the total oxidation reactions.

In this study toluene has been chosen as VOC probe molecule because aromatics are regular constituents of industrial and automotive emissions and since toluene presents an important POCP (Photochemical Ozone Creativity Potential).

In the present study the influence of structure peculiarities of SBA-15 and SBA-16 materials on the formation of copper and iron oxide nanoparticles during the incipient wetness impregnation and their catalytic behavior in total oxidation of toluene were investigated.

\section{EXPERIMENTAL}

\subsection{Synthesis}

The parent silica SBA-15 and SBA-16 materials were synthesized according to the well known procedures of Zhao et al. [34]. Pluronic P123 and F127 (BASF) triblock copolymers were used as templates, respectively and tetraethylortosilicate (TEOS) as silica source. The relative molar compositions of the synthesis mixtures for SBA-15 and SBA-16 were the following:

SBA-15: 4 g PEO $_{20} \mathrm{PPO}_{70} \mathrm{PEO}_{20}$ : $0.24 \mathrm{HCl}$ : 0.04 TEOS: $7.86 \mathrm{H}_{2} \mathrm{O}$

SBA-16: 4 g PEO ${ }_{106} \mathrm{PPO}_{70} \mathrm{PEO}_{106}$ : $0.24 \mathrm{HCl}$ : 0.04 TEOS: $7.86 \mathrm{H}_{2} \mathrm{O}$.

The synthesis mixture of SBA-15 was kept under stirring at $313 \mathrm{~K}$ for $24 \mathrm{~h}$ than put in a teflon lined autoclave and hydrothermally treated at $373 \mathrm{~K}$ for $24 \mathrm{~h}$. SBA-16 was stirred at room temperature for $20 \mathrm{~h}$, than hydrothermally treated at $353 \mathrm{~K}$ for $48 \mathrm{~h}$.

Template was removed by calcination in air at $723 \mathrm{~K}$ for SBA-15 and at $773 \mathrm{~K}$ for SBA-16 with a heating rate of $1 \mathrm{~K} / \mathrm{min}$. 
An incipient wetness impregnation technique with copper and iron nitrates was applied for loading of $9 \mathrm{wt}$. \% of copper and $3 \mathrm{wt}$. or $4.5 \mathrm{wt}$. \% of iron. The precursor salts were decomposed in air at $773 \mathrm{~K}$ for 2 hours.

\subsection{Characterization}

X-ray diffraction patterns were recorded by Philips PW 1810/3710 diffractometer applying monochromatized $\mathrm{CuK}_{\alpha}$ radiation $(40 \mathrm{kV}, 35 \mathrm{~mA})$. Crystallite size of the metal oxides was determined by the Sherrer equation evaluating the FWMH values with full profile fitting method. Metal oxide and metallic phases were determined based on JSPDS ICDD database, the corresponding ICDD card numbers were: $\mathrm{CuO} 44-706, \mathrm{CuFe}_{2} \mathrm{O}_{4}$ 72-1174, $\mathrm{Cu}$ 4-836, Fe 6-696. In situ XRD measurements were carried out in different atmospheres $\left(\mathrm{H}_{2}, \mathrm{O}_{2} / \mathrm{He}, 60 \mathrm{~cm}^{3} / \mathrm{min}\right)$ in a high temperature HTK-1200 Anton-Paar chamber with temperature programming. Patterns were recorded between 25 and $65^{\circ} 2 \theta$ with $0.02^{\circ}$ step size for $1 \mathrm{sec}$. Semi-quantitative determination of different metal oxide phases was carried out by full profile fitting based on RIR (Relative Intensity Ratio) method applying corundum as an inner standard.

Nitrogen physisorption measurements were carried out at $77 \mathrm{~K}$ using Quantachrome NOVA Automated Gas Sorption Instrument. Samples were outgassed under vacuum at $623 \mathrm{~K}$ for $24 \mathrm{~h}$. The specific surface area was calculated by the BET method in the range of relative pressures from 0.02 to 0.1 . The pore-size distributions of SBA-15 supported samples were calculated from the desorption branch of isotherms by the BJH method. For SBA-16 supported samples NLDFT method were used to calculate the pore sizes applying the model ' $\mathrm{N}_{2}$ adsorption at $77 \mathrm{~K}$ on silica with cylindrical/spherical pores, adsorption brach' in program Quantachrom Autosorb 1, v1.53.

TEM images were taken by using a MORGAGNI 268D TEM (100 kV; W filament; pointresolution $=0.5 \mathrm{~nm}$ ). Samples were suspended in small amount of ethanol and a drop of suspension was deposited onto copper grid covered by carbon supporting film and dried at ambient.

The reducibility of $\mathrm{Cu}$ and $\mathrm{Fe}$ modified samples were investigated by temperature-programmed reduction (TPR) technique in $\mathrm{H}_{2} / \mathrm{Ar}$ flow $(10: 90,20 \mathrm{ml} / \mathrm{min}$ ) using a conventional TPR apparatus equipped with a heat conductivity cell and a trap for removal of released water. Before TPR run samples were pretreated in oxygen at $623 \mathrm{~K}$ for $1 \mathrm{~h}$. Reduction degree of metal oxide species was estimated by measuring the hydrogen uptake of the samples, calibrated by commercial bulk $\mathrm{CuO}$. TPR curves were normalized to $1 \mathrm{~g}$ sample calcined at $1273 \mathrm{~K}$.

Diffuse reflectance spectra in the UV-Vis region were detected at ambient by a Jasco V-670 UVVis spectrophotometer equipped with NV-470 type integrating sphere using the official $\mathrm{BaSO}_{4}$ standard as reference.

${ }^{57} \mathrm{Fe}$ Mössbauer spectroscopic measurements (MS) were performed by a KFKI spectrometer, operating in constant acceleration mode with ${ }^{57} \mathrm{Co} / \mathrm{Rh}$ source $(0.5 \mathrm{GBq})$. The positional parameters are related to alpha-iron standard. The accuracy of these data is ca. $\pm 0.03 \mathrm{~mm} / \mathrm{s}$. In situ spectra were recorded at room temperature $(300 \mathrm{~K})$. Samples were first measured in their ambient state containing moisture adsorbed from air. In the following step, samples were treated in hydrogen at $630 \mathrm{~K}$ for $2 \mathrm{~h}$ and measurements were carried out in hydrogen atmosphere afterwards. The following parameters were extracted from the spectral components by computer fitting: isomer shift (IS), quadrupole splitting (QS), internal magnetic hyperfine field (MHF), and relative intensities of components (RI).

\subsection{Catalytic activity measurements}

Prior to the catalytic tests samples were pretreated for 1 hour in air up to $723 \mathrm{~K}$. Toluene oxidation was studied at atmospheric pressure using a fixed-bed flow reactor with air as carrier gas (30 $\mathrm{ml} / \mathrm{min}$ ). In the reaction $30 \mathrm{mg}$ sample (particle size 0.2-0.8 mm) was tested, diluted with $60 \mathrm{mg}$ glass beads of the same diameter, previously checked to be inactive. The reactor itself was a quartz tube of $15 \mathrm{~mm}$ inner diameter, with the catalyst bed at the middle. A thermocouple was positioned 
in the catalyst bed for accurate measurement of the catalyst temperature. All gas lines of the apparatus were heated continuously at $383 \mathrm{~K}$ in order to minimize VOC adsorption on the tube walls. The air stream passed through a saturator filled with toluene and equilibrated at $273 \mathrm{~K}$ $\left(\mathrm{p}_{\text {toluene }}=0.9 \mathrm{kPa}\right)$. The reactant was fed in the reactor with a flow rate of $30 \mathrm{ml} / \mathrm{min}$ and catalytic tests were carried out in the temperature range 523-723 K at WHSV of $1.2 \mathrm{~h}^{-1}$. The reaction steady state was established after $30 \mathrm{~min}$ in each temperature. On-line analysis of the reaction products was performed using HP-GC equipped with FID and TCD detectors applying a Carboxen 1100 packed column, and a HP5 50 m capillary column.

\section{RESULTS AND DISCUSSION}

\subsection{Physico-chemical properties}

XRD data of the copper and iron modified silica materials in the low two theta region (not shown) confirm the preservation of the mesopore structure after the impregnation process. In the higher two theta region, reflections with low intensity, characteristic for $\mathrm{CuO}$ were detected on all the studied materials. No reflections typical of iron oxide species could be observed on bicomponent materials for both supports (Fig. 1).

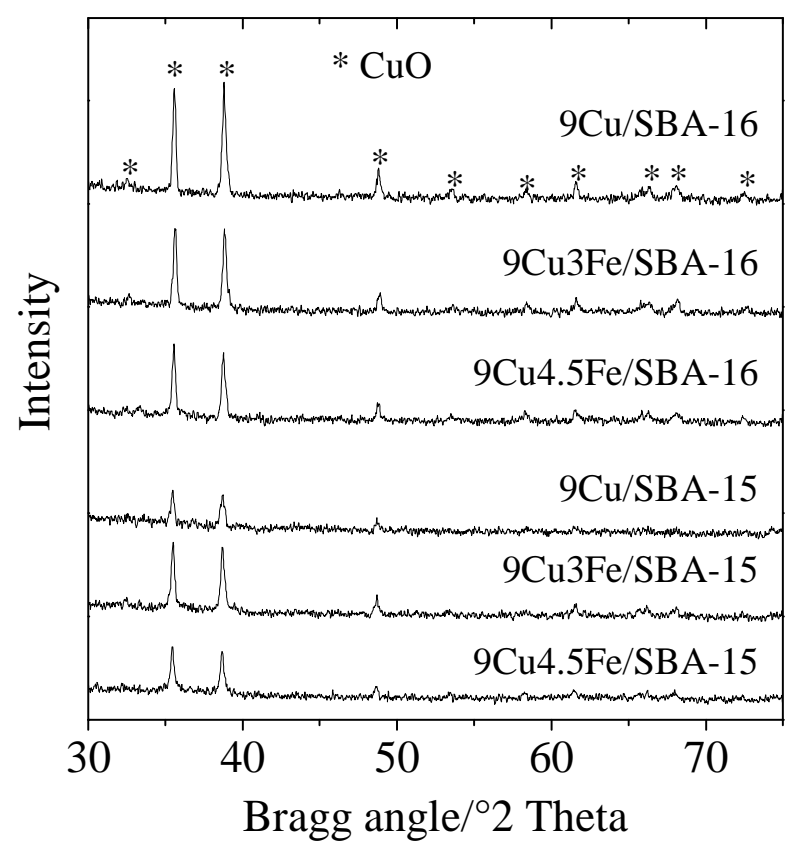

Figure 1. XRD patterns of the SBA-15 (A) and SBA-16 (B) supported copper and iron containing samples

Crystallite size of copper oxide particles determined by the Scherrer method can be found in Table 1. Significant differences can be found in crystallite sizes between the different supports, the average crystallite size is about 100-120 nm for SBA-15 support, whereas 200-300 nm for SBA16. Formation of smaller amount of metal oxide was detected in the case of SBA-15 support compared to SBA-16 support. These observations can be explained by the easier penetration of the impregnating salt into the straight channels of SBA-15 materials. 
Table 1 Physico-chemical properties of the studied samples

\begin{tabular}{llllll}
\hline Samples & $\begin{array}{l}\mathrm{S}_{\mathrm{BET}} \\
\left(\mathrm{m}^{2} / \mathrm{g}\right)\end{array}$ & $\begin{array}{l}\mathrm{PD}^{\mathrm{a}} \\
(\mathrm{nm})\end{array}$ & $\begin{array}{l}\text { Pore volume } \\
\left(\mathrm{cm}^{3} / \mathrm{g}\right)\end{array}$ & $\begin{array}{l}\mathrm{CuO} \text { cryst. size } \\
(\mathrm{nm})\end{array}$ & $\begin{array}{l}\text { Extent of reduction up } \\
\text { to } 1073 \mathrm{~K}^{\mathrm{c}},(\%)\end{array}$ \\
\hline SBA-15 & 756 & 6.0 & 1.0 & - & - \\
9Cu/SBA-15 & 615 & 4.71 & 0.75 & $100 \pm 30$ & 100 \\
9Cu3Fe/SBA-15 & 609 & 5.05 & 0.76 & $120 \pm 30$ & 100 \\
9Cu4.5Fe/SBA-15 & 602 & 5.05 & 0.75 & $120 \pm 30$ & 92 \\
SBA-16 & 1128 & $7.90(2.5)$ & 0.64 & - & - \\
9CuSBA-16 & 705 & $7.55(2.5)$ & 0.43 & $330 \pm 90$ & 100 \\
$9 \mathrm{Cu} 3$ FeSBA-16 & 611 & $7.86(2.5)$ & 0.39 & $200 \pm 60$ & 90 \\
$9 \mathrm{Cu} 4.5 \mathrm{Fe} / \mathrm{SBA}-16$ & 570 & $7.83(2.5)$ & 0.37 & $200 \pm 60$ & 85
\end{tabular}

${ }^{\mathrm{a}}$ Pore diameter calculated by the BJH method (desorption branch) for SBA-15 samples and by NLDFT method for SBA-16 samples (adsorption branch)

${ }^{\mathrm{b}}$ Determined by XRD method using the Sherrer equation

${ }^{\mathrm{c}} \mathrm{H}_{2}$ consumption related to the calculated theoretical value* needed for the reduction of $\mathrm{Cu}^{2+}$ and $\mathrm{Fe}^{3+}$ ions to metallic state $* 2.65 \mathrm{mmol} / \mathrm{g}$ for $9 \% \mathrm{Cu}$ and $4.5 \% \mathrm{Fe}, 2.22 \mathrm{mmol} / \mathrm{g}$ for $9 \% \mathrm{Cu}$ and $3 \% \mathrm{Fe}$, and $1.42 \mathrm{mmol} / \mathrm{g}$ for $9 \% \mathrm{Cu}$ containing samples)

In Fig. 2 nitrogen physisorption isotherms of metal-containing silica materials are presented. The corresponding calculated parameters are listed in Table 1. Compared to parent supports a 20-30\% decrease in specific surface area and pore volume can be observed on metal oxide modified samples. Pore diameters are reduced from 6 to $5 \mathrm{~nm}$ in SBA-15 supported samples, whereas no significant pore size reduction can be observed in SBA-16 supported catalysts either in the spherical pores $(\sim 8 \mathrm{~nm})$ or in the interconnecting channels $(2.5 \mathrm{~nm})$. These data support that a part of metal oxides penetrated into the channels and cavities of mesoporous supports, but no significant pore blocking occurred.

TEM images of the samples confirmed our former results (Fig. 3). On SBA-15 silica impregnating metal-salts can penetrate into the channels and finely dispersed oxide nanoparticles can be seen inside the pores, but formation of bigger particles on the outer surface can also be observed. On SBA-16 support formation of bigger particles on the outer surface is predominant and hardly any nanoparticles can be detected inside the pores. This observation is also in accordance with XRD results showing higher amount of metal-oxide phase on SBA-16 support.

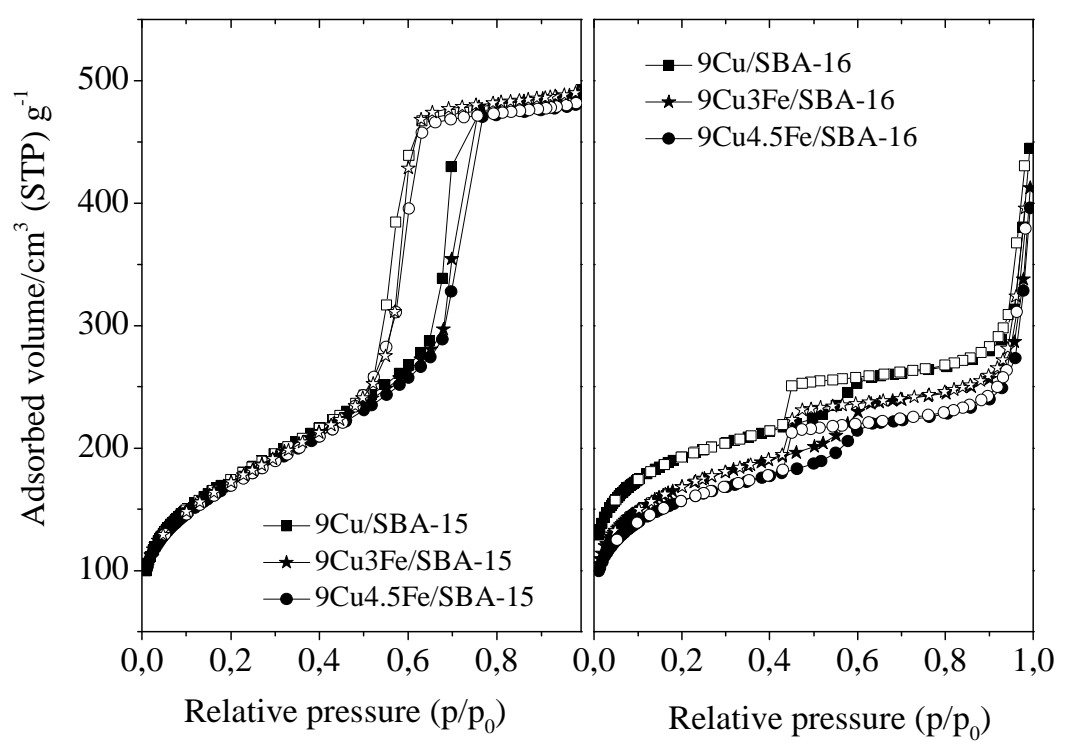

Figure 2. Nitrogen adsorption/desorption isotherms of the copper and iron modified SBA-15 and SBA-16 samples after salt decomposition at $773 \mathrm{~K}$ 


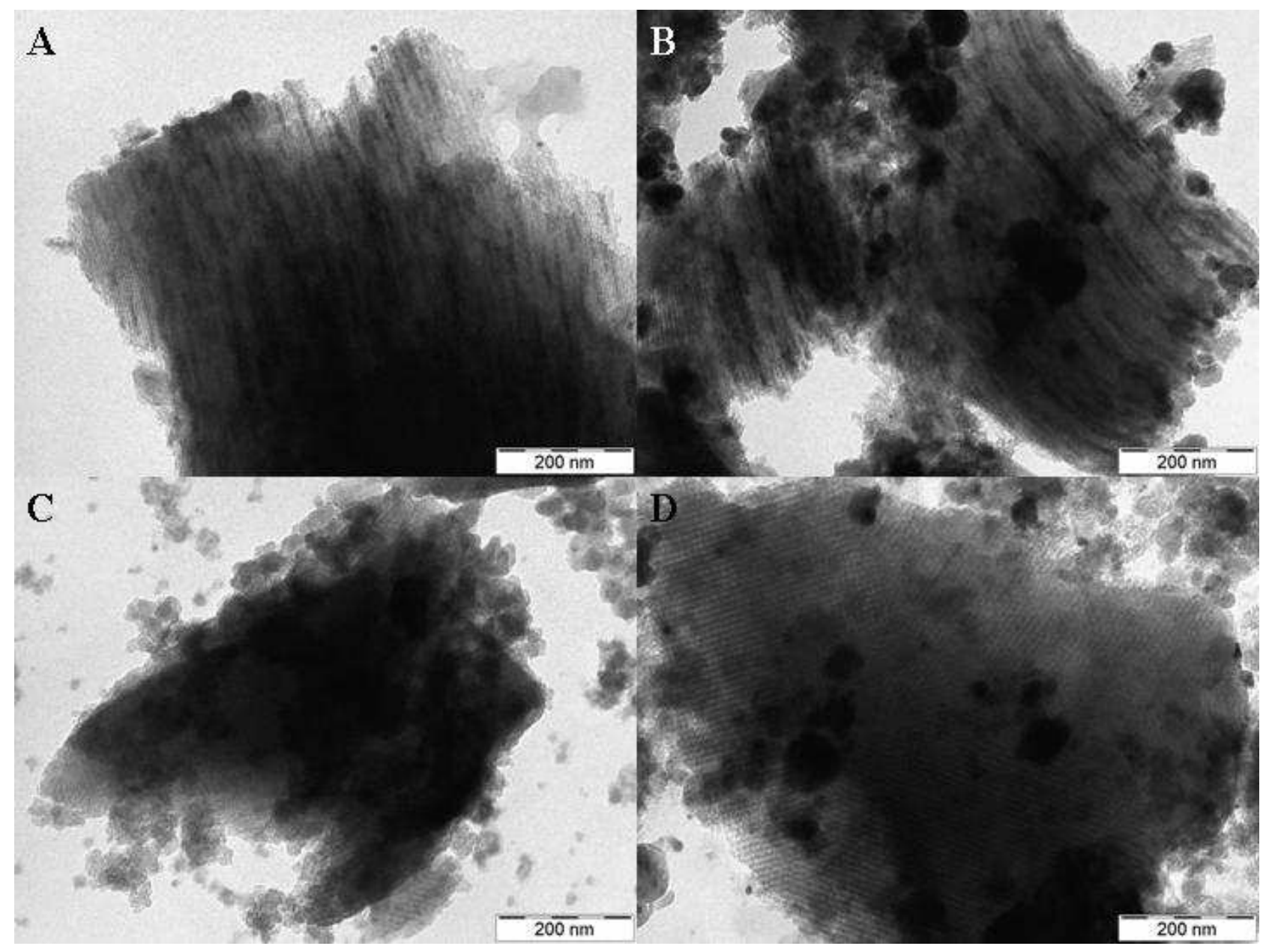

Figure 3. TEM images of the copper and iron modified SBA-15 and SBA-16 samples (A: 9Cu3Fe/SBA-15, B: 9Cu4.5Fe/SBA-15, C: 9Cu3Fe/SBA-16, D: 9Cu4.5Fe/SBA-16)

DR UV-Vis spectra (Fig. 4) recorded at room temperature are used for the characterization of oxidation and coordination state of copper and iron oxide species of the modified SBA-15 and SBA-16 samples. In the spectrum of copper loaded SBA-15 sample (Fig. 4 A) the bands characteristic for mononuclear $\mathrm{Cu}^{2+}$ as well as $[\mathrm{Cu}-\mathrm{O}-\mathrm{Cu}]_{\mathrm{n}}$ cluster species can be observed at 250 , and at $300 \mathrm{~nm}$, respectively. A band associated with the d-d transition of $\mathrm{Cu}^{2+}$ in octahedral environment, e.g. in a separate $\mathrm{CuO}$ phase can also be identified between 670 and $740 \mathrm{~nm}$. For bimetallic samples two intensive bands at about $500 \mathrm{~nm}$ and $720 \mathrm{~nm}$ can be observed. The former one can be associated with the formation of copper ferrite $\left(\mathrm{CuFe}_{2} \mathrm{O}_{4}\right)$ phase, the latter one can be attributed to the presence of oligomeric $\mathrm{FeOx}$ clusters and finely dispersed hematite like nanoparticles, respectively. For 9CuSBA-16 sample an intensive band for mononuclear $\mathrm{Cu}^{2+}$ can be observed at $240 \mathrm{~nm}$ and in contrast to SBA-15 support not oligomeric species were detected. This fact is in accordance with our former TEM results showing the absence of metal-oxide nanoparticles inside the channels. Also the formation of crystalline copper oxide phase is evidenced between 670 and $740 \mathrm{~nm}$. Addition of the iron component resulted in the appearance of FeOx species at lower wavelength than in the case of SBA-15 support, at about $350 \mathrm{~nm}$. The presence of finely dispersed, crystalline $\mathrm{CuO}$ and $\mathrm{Fe}_{2} \mathrm{O}_{3}$ nanoparticles can be detected over 600 $\mathrm{nm}$. Increasing the iron content to $4.5 \mathrm{wt}$. \% a clear shift can be seen to higher wavelength for both supports over $400 \mathrm{~nm}$, more pronounced for SBA-16. This is an indication for the formation of higher amount of oligomeric $\mathrm{FeO}_{\mathrm{x}}$ clusters with increasing iron content. 

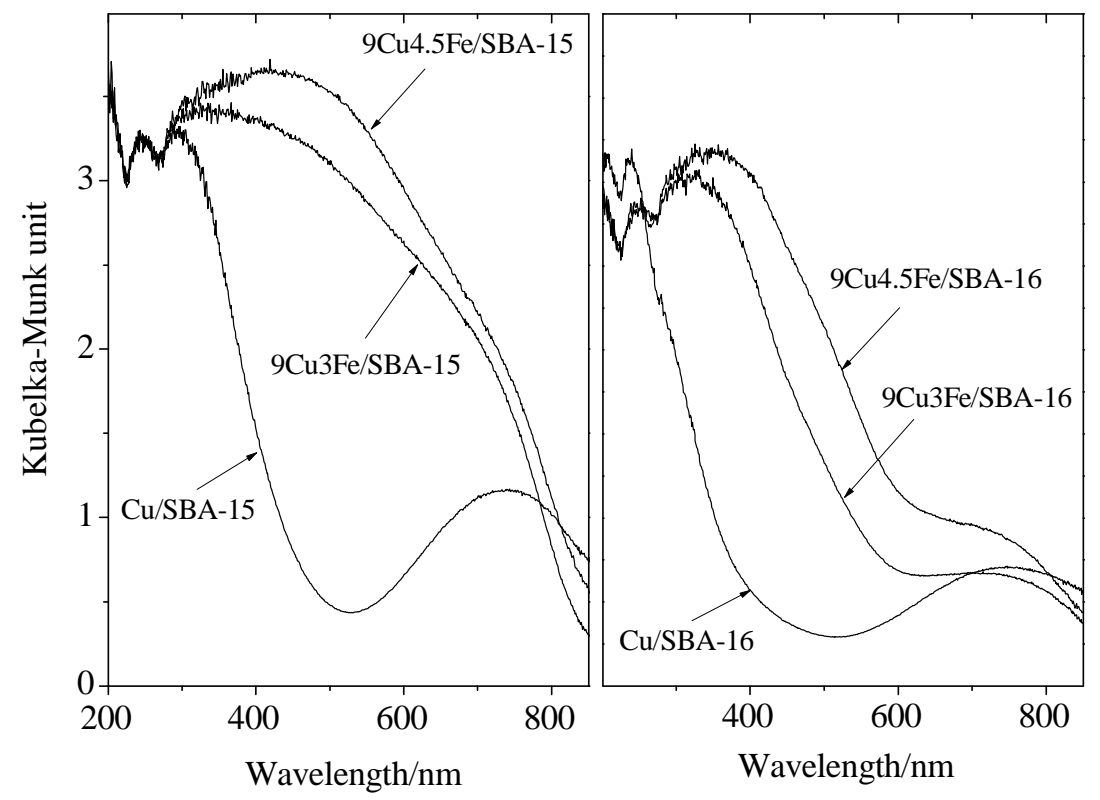

Figure 4. DRIFT UV-Vis spectra of the copper and iron modified SBA-15 and SBA-16 catalysts

The absence of intensive $500 \mathrm{~nm}$ band characteristic for copper ferrite phase on SBA-16 support is also remarkable. Formation of copper ferrite phase on bimetallic SBA-15 materials was not evidenced by XRD, which can be explained by its fine dispersion, i.e. the crystallites are smaller than $5 \mathrm{~nm}$. Our former study on cobalt and iron containing SBA-15 and MCM-41 materials [35] helped us to interpret the UV-Vis result. We have found that on SBA-15 support cobalt ferrite phase was formed with an intensive band at $500 \mathrm{~nm}$, whereas on the narrow pore MCM-41 support separation of the oxide phases to cobalt and iron oxide could be observed. Similar phenomenon can now be found in copper and iron containing SBA-15 and SBA-16 supports. Also the color of the samples is very different, bimetallic SBA-15 samples are black, whereas SBA-16 ones are brownish. Direct evidence for the formation of finely dispersed copper oxide phase can be accumulated by means of in situ high temperature XRD measurements (Fig. 5). 9Cu4.5Fe/SBA-15 and SBA-16 samples were heat treated at 873 and $973 \mathrm{~K}$ in $\mathrm{O}_{2} / \mathrm{He}$ gas in order to increase the crystallite size of ferrite phase by agglomeration. The existence of a small amount of copper ferrite phase following the $973 \mathrm{~K}$ heat treatment can be observed on SBA-15 support, whereas on SBA-16 support the appearance of separate $\mathrm{Fe}_{2} \mathrm{O}_{3}$ phase can be detected. These observations are in accordance with our former results, that in narrower pores separation of metal-oxide phases occurs due to the reaction of surface silanol groups with the metal ions during the impregnation process [35]. Our XRD profile fitting calculations on ferrite containing sample showed that the amounts of copper ferrite and copper-oxide phases are almost equal (7-6.5\%), and the crystallite size of the ferrite phase is about $7 \mathrm{~nm}$. Reduction behavior of the metal-oxide modified samples was characterized by temperature programmed reduction (TPR) method. The TPR curves of the studied catalysts are shown in Fig. 6. In all samples reduction of finely dispersed separate copper oxide phase can be observed with the appearance of an intensive peak at $523 \mathrm{~K}$. This reduction temperature is lower than that of bulk commercial $\mathrm{CuO}$ between 523 and $623 \mathrm{~K}$, and it is probably due to the smaller crystallite size. During the impregnation procedure a part of copper can react with the silanol groups of the support and these copper silicate species can be reduced to metallic state at higher temperatures, up to 673-773 K [10]. Therefore in copper-containing samples a second reduction peak can be observed at 673-773 K. 


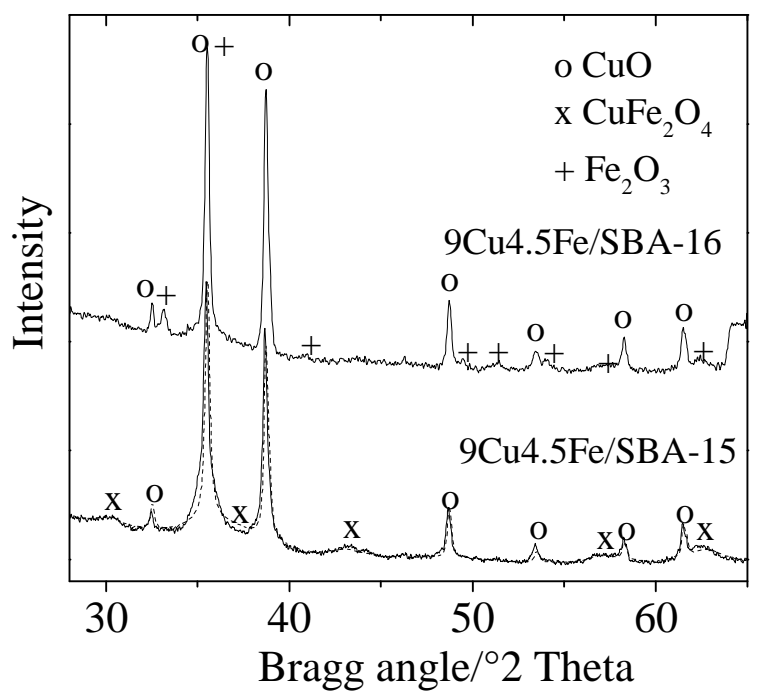

Figure 5. High temperature in situ XRD patterns of $9 \mathrm{Cu} 4.5 \mathrm{Fe} / \mathrm{SBA}-15$ and SBA-16 samples heat treated at $973 \mathrm{~K}$ in $\mathrm{O}_{2} / \mathrm{He}$. Dashed line pattern of $9 \mathrm{Cu} 4.5 \mathrm{Fe} / \mathrm{SBA}-15$ sample is its simulated pattern, calculated with profile fitting method using copper ferrite and copper oxide phases

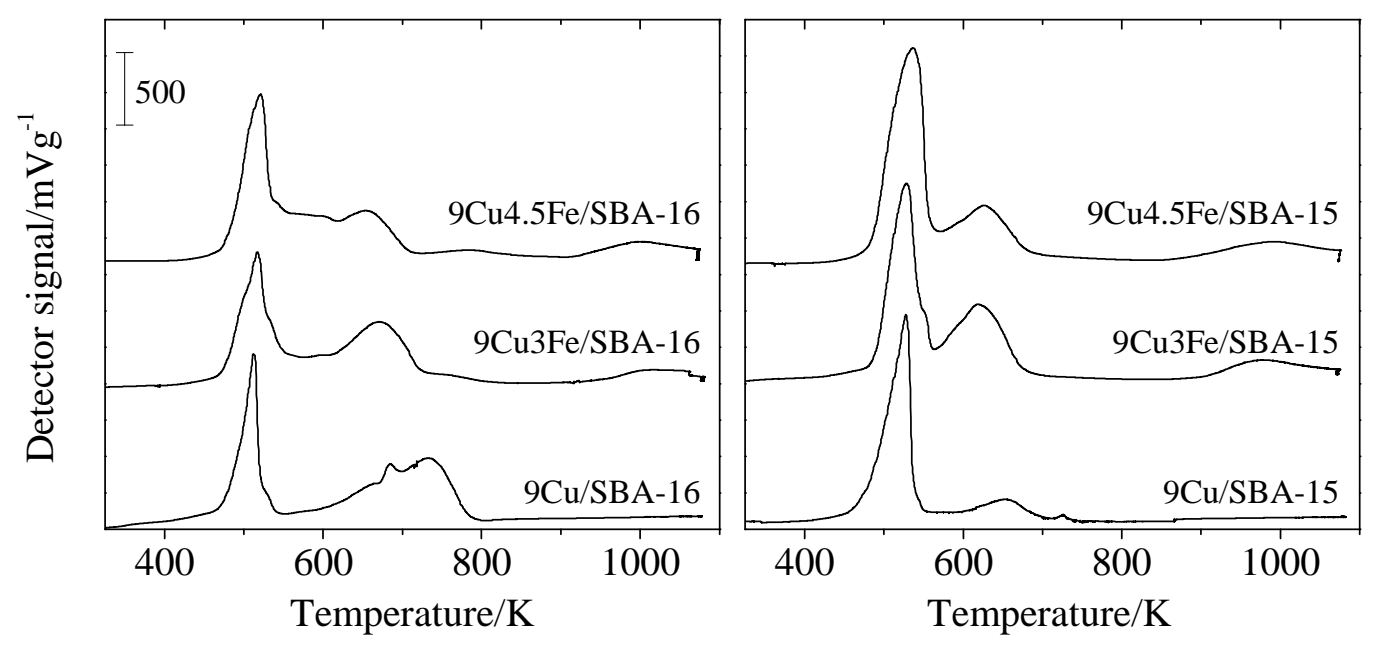

Figure 6. TPR curves of the copper and iron modified SBA-15 and SBA-16 samples

The latter one is more pronounced and shifted to higher temperature for $9 \mathrm{Cu} / \mathrm{SBA}-16$ sample. The extent of reduction is $100 \%$ for both monocomponent catalysts, copper oxide on both supports can be totally reduced up to $723 \mathrm{~K}$ (Table 1). In iron and copper containing SBA-15 samples the first $523 \mathrm{~K}$ peak is broadened and the second reduction peak appears at about $623 \mathrm{~K}$. With increasing amount of iron the intensity of the $623 \mathrm{~K}$ peak is slightly decreased and the $523 \mathrm{~K}$ peak increased. These changes are indicating that in the presence of iron higher amount of $\mathrm{CuO}$ phase is formed because the interaction of copper with the silica wall is hindered. According to our former investigations [10], copper on mesoporous silica materials can be reduced to metallic state up to $670 \mathrm{~K}$, however, on iron containing catalysts total reduction cannot be achieved up to $873 \mathrm{~K}$. This can be explained by the stabilization of a part of $\mathrm{Fe}^{3+}$ species in the silica matrix by the reaction with silanol groups [36]. These kinds of $\mathrm{Fe}^{3+}$ can be reduced up to $873 \mathrm{~K}$ only to $\mathrm{Fe}^{2+}$ state and their total reduction to metallic state proceeds only over $1073 \mathrm{~K}$. Consequently, on iron containing samples the higher temperature peaks $(623-673 \mathrm{~K})$ can be associated with the reduction of iron containing phases in different forms, such as small $\mathrm{Fe}_{2} \mathrm{O}_{3}$ nanoclusters, copper ferrite, and ionic 
iron species connected to silica wall. On all iron containing samples a wide peak can be observed between 970-1073 K, which can be associated with the reduction of the latter ionic iron species to metallic state. These observations are in accordance with out XRD result, showing the lack of highly crystalline iron oxide phase in the channels or on the outer surface of the supports. Reduction of iron containing phases on SBA-16 supported bimetallic catalysts proceeds in two steps between 573 and $673 \mathrm{~K}$. The lower temperature peak can probably be associated with the reduction of finely dispersed $\mathrm{Fe}_{2} \mathrm{O}_{3}$ phase, and the higher one with the ionic iron silicate species. Due to the strong interaction of iron with the support primarily iron oxide nanoclusters can be formed in the channels of the mesoporous materials. If the size of the channels allows it, they can react with the finely dispersed copper ions to form a ferrite phase.

In situ Mössbauer spectroscopy was applied to access complementary information on the various local environments of iron in the samples. Measurements were performed at ambient temperature in a three step procedure. Spectra were first recorded on the samples containing adsorbed water. In the next stage samples were evacuated at $663 \mathrm{~K}$ for $2 \mathrm{~h}$. Finally, samples were treated in hydrogen at $663 \mathrm{~K}$ for $2 \mathrm{~h}$. Spectra were collected in two velocity ranges, $\pm 12 \mathrm{~mm} / \mathrm{s}$, and $\pm 4 \mathrm{~mm} / \mathrm{s}$. The former, broad range provides information on the total amount of iron, whereas the narrow \pm 4 $\mathrm{mm} / \mathrm{s}$ range displays only the central part of spectra in improved resolution. $\pm 12 \mathrm{~mm} / \mathrm{s}$ spectra collected on SBA-15 and SBA-16 samples are displayed in Figs. 7 and 8. The corresponding parameters obtained from their decomposition are shown in Table 2. The parent samples containing adsorbed water show a typical doublet characteristic for iron oxide phase with $\mathrm{Fe}^{3+}$ oxidation state and octahedral coordination. In the higher resolution spectra this doublet can be decomposed to two types of components with different QS values $(0.6$ and $1.05 \mathrm{~mm} / \mathrm{s})$ indicating different coordination symmetries. These parameters are characteristic for finely dispersed ironoxide species and ionic iron species connected to the silica matrix through oxygen atoms, respectively [36]. Besides, the appearance of a magnetic sextet on the SBA-16 support and the absence of it on the SBA-15 spectra are apparent (Figs. 7 and 8, top). The detected magnetic splitting is ca. 50 Tesla, characteristic of antiferromagnetic oxides.

Table 2 Mössbauer parameters of iron containing samples extracted from $\pm 12 \mathrm{~mm} / \mathrm{s}$ spectra (Figs. 7 and 8)

\begin{tabular}{|c|c|c|c|c|c|c|c|c|c|}
\hline \multirow[t]{2}{*}{ Samples } & \multirow[b]{2}{*}{ Comp. } & \multicolumn{4}{|c|}{$9 \mathrm{Cu} 4.5 \mathrm{Fe} / \mathrm{SBA}-15$} & \multicolumn{4}{|c|}{ 9Cu3Fe/SBA-15 } \\
\hline & & $\begin{array}{l}\mathrm{IS} \\
\mathrm{mm} / \mathrm{s}\end{array}$ & $\begin{array}{l}\mathrm{QS} \\
\mathrm{mm} / \mathrm{s}\end{array}$ & $\begin{array}{l}\text { MHF } \\
\text { Tesla }\end{array}$ & $\begin{array}{l}\text { Rel. Int. } \\
\%\end{array}$ & $\begin{array}{l}\mathrm{IS} \\
\mathrm{mm} / \mathrm{s}\end{array}$ & $\begin{array}{l}\mathrm{QS} \\
\mathrm{mm} / \mathrm{s}\end{array}$ & $\begin{array}{l}\text { MHF } \\
\text { Tesla }\end{array}$ & $\begin{array}{l}\text { Rel. Int. } \\
\%\end{array}$ \\
\hline Parent & $\mathrm{Fe}^{3+}$ & 0.34 & 0.80 & - & 100 & 0.34 & 0.80 & - & 100 \\
\hline $\mathrm{H}_{2}$ red. & $\mathrm{Fe}^{2+}$ & 1.15 & 1.76 & - & 51 & 1.11 & 1.79 & - & 57 \\
\hline \multirow[t]{2}{*}{$660 \mathrm{~K}$} & $\mathrm{Fe}(0) \mathrm{m}^{\mathrm{a}}$ & 0.01 & - & 32.2 & 37 & 0.00 & - & 32.1 & 31 \\
\hline & $\mathrm{Fe}(0) \mathrm{s}^{\mathrm{b}}$ & 0.00 & - & - & 11 & -0.04 & - & - & 12 \\
\hline \multicolumn{2}{|l|}{ Samples } & \multicolumn{4}{|c|}{$9 \mathrm{Cu} 4.5 \mathrm{Fe} / \mathrm{SBA}-16$} & \multicolumn{4}{|c|}{$9 \mathrm{Cu} 3 \mathrm{Fe} / \mathrm{SBA}-16$} \\
\hline \multirow[t]{2}{*}{ Parent } & $\mathrm{Fe}^{3+}$ & 0.34 & 0.88 & - & 74 & 0.30 & 0.94 & - & 76 \\
\hline & $\mathrm{Fe}^{3+} \mathrm{m}^{\mathrm{c}}$ & 0.30 & 0.20 & 50.3 & 26 & 0.37 & 0.26 & 50.3 & 24 \\
\hline $\mathrm{H}_{2}$ red. & $\mathrm{Fe}^{2+}$ & 1.09 & 1.87 & - & 58 & 1.12 & 1.86 & - & 70 \\
\hline \multirow[t]{2}{*}{$660 \mathrm{~K}$} & $\mathrm{Fe}(0) \mathrm{m}^{\mathrm{a}}$ & -0.01 & - & 33.0 & 33 & -0.01 & - & 33.0 & 18 \\
\hline & $\mathrm{Fe}(0) \mathrm{s}^{\mathrm{b}}$ & -0.05 & - & - & 8 & -0.04 & - & - & 12 \\
\hline
\end{tabular}




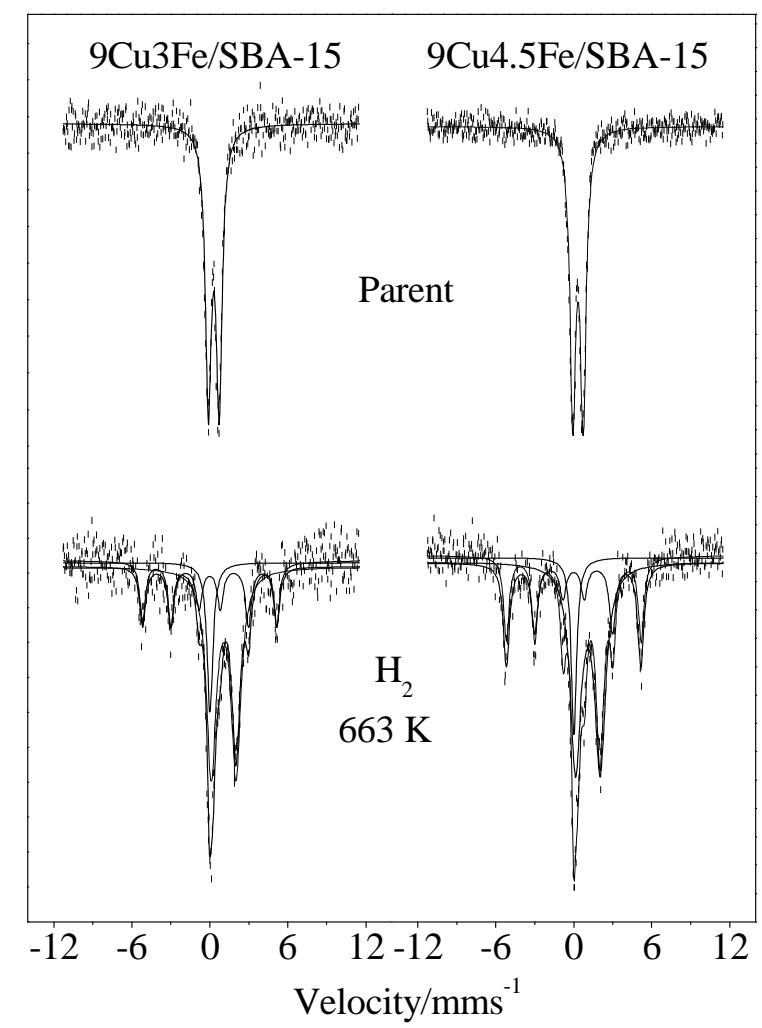

Figure 7. ${ }^{57} \mathrm{Fe}$ Mössbauer spectra of the copper and iron modified SBA-15 materials

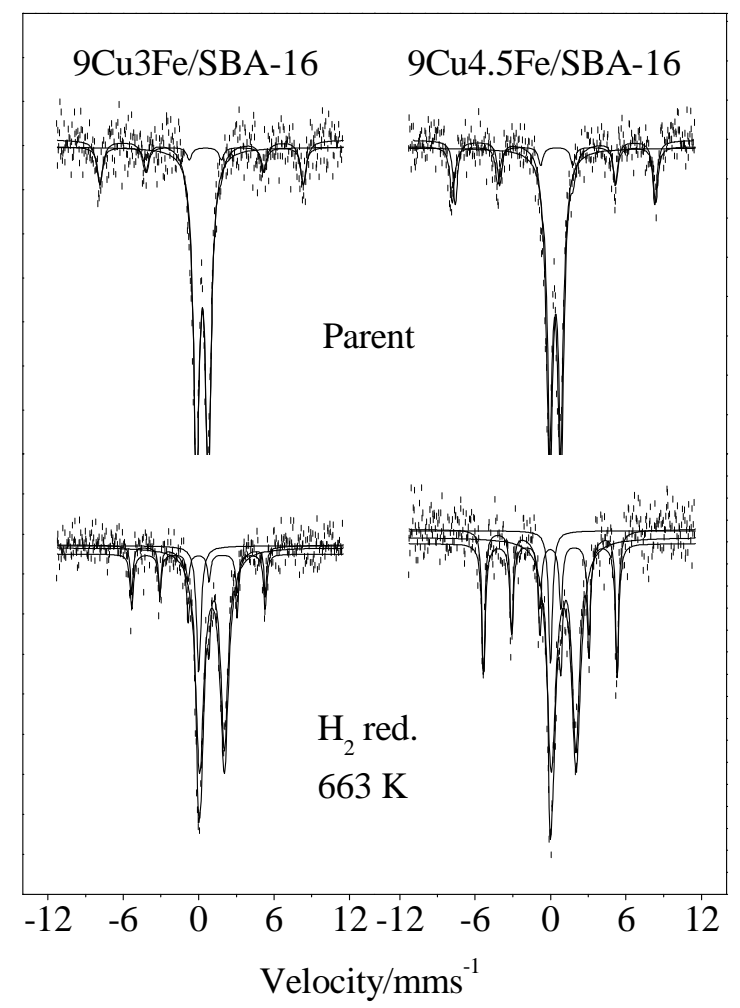

Figure 8. ${ }^{57} \mathrm{Fe}$ Mössbauer spectra of the copper and iron modified SBA-16 materials 
The difference in the appearance is correlated with the size of agglomerated oxidic Fe entities with Fe-O-Fe chains. The sextet component appears if the size of the oxidic particles exceeds $10-20 \mathrm{~nm}$ [37]. Thus, 24-26\% of iron in the SBA-16 samples form particles with diameter exceeding this size (Table 2). These observations support our former XRD results with the formation of iron oxide phase on SBA-16 support. In contrast, the mean diameter of dominant part of iron-oxidic particles is smaller on the SBA-15 support. Because of the similarity of Mössbauer parameters of iron-oxide and ferrite nanoclusters [38] a separate ferrite phase can not be distinguished on SBA15 support. Our results show that the dominant part of iron in both supports is distributed evenly in high dispersion. Simple evacuation has a detectable effect - namely the quadrupole splitting increases and even $\mathrm{Fe}^{3+} \Rightarrow \mathrm{Fe}^{2+}$ (auto)reduction proceeds in a small extent. The removal of the adsorbed water from the proximity of the $\mathrm{Fe}^{3+}$ ions decreases the charge symmetry around them as reflected in the increase of QS values (not shown). This phenomenon may proceed only with those iron ions that are connected to the support in very high dispersion. Reducing the samples at $663 \mathrm{~K}$ in hydrogen a doublet characteristic for $\mathrm{Fe}^{2+}$ species can be registered. The amount of divalent iron is about $50-70 \%$, and it is in good accordance with our TPR data showing the partial reduction of $\mathrm{Fe}^{3+}$ to $\mathrm{Fe}^{0}$. Iron and copper are in close vicinity of each other. In spectra recorded after the $663 \mathrm{~K}$ reduction in hydrogen also a ferromagnetic sextet appears with 33 Tesla internal magnetic field. This value is primarily characteristic for metallic iron. The reduction of $\mathrm{Fe}_{2} \mathrm{O}_{3}$ without copper in hydrogen to metallic iron proceeds only at higher temperatures. Furthermore another, single-line component is also present in these spectra at isomer shift $\sim 0.0 \mathrm{~mm} / \mathrm{s}$, which can be attributed to copper-iron bimetallic component (Table 2).

High temperature in situ XRD measurements carried out in $\mathrm{H}_{2}$ atmosphere up to $873 \mathrm{~K}$ on 9Cu4.5Fe/SBA-15 and SBA-16 samples confirmed our Mössbauer and TPR results (Fig. 9). On both supports reduction of $\mathrm{CuO}$ to copper starts at low temperature. At 473 both $\mathrm{CuO}$ and $\mathrm{Cu}$ phases can be observed. However, total reduction to metallic copper proceeds up to $573 \mathrm{~K}$ and at higher temperatures only the agglomeration of metallic particles can be observed as evidenced by the decrease of FWMH values of the reflections. According to the Sherrer equation after $873 \mathrm{~K}$ reduction the crystallite size of metallic copper particles is $55 \mathrm{~nm}$ for SBA-15 and $165 \mathrm{~nm}$ for SBA-16 support. Reduction of iron oxide species to metallic iron begins at $573 \mathrm{~K}$, but more pronounced from $673 \mathrm{~K}$. It can be observed that on SBA-16 support iron is formed in bigger crystallites owing to the lower FWMH values. Reflections of metallic iron on SBA-15 support are broadened even at $873 \mathrm{~K}$, indicating very finely dispersed species.

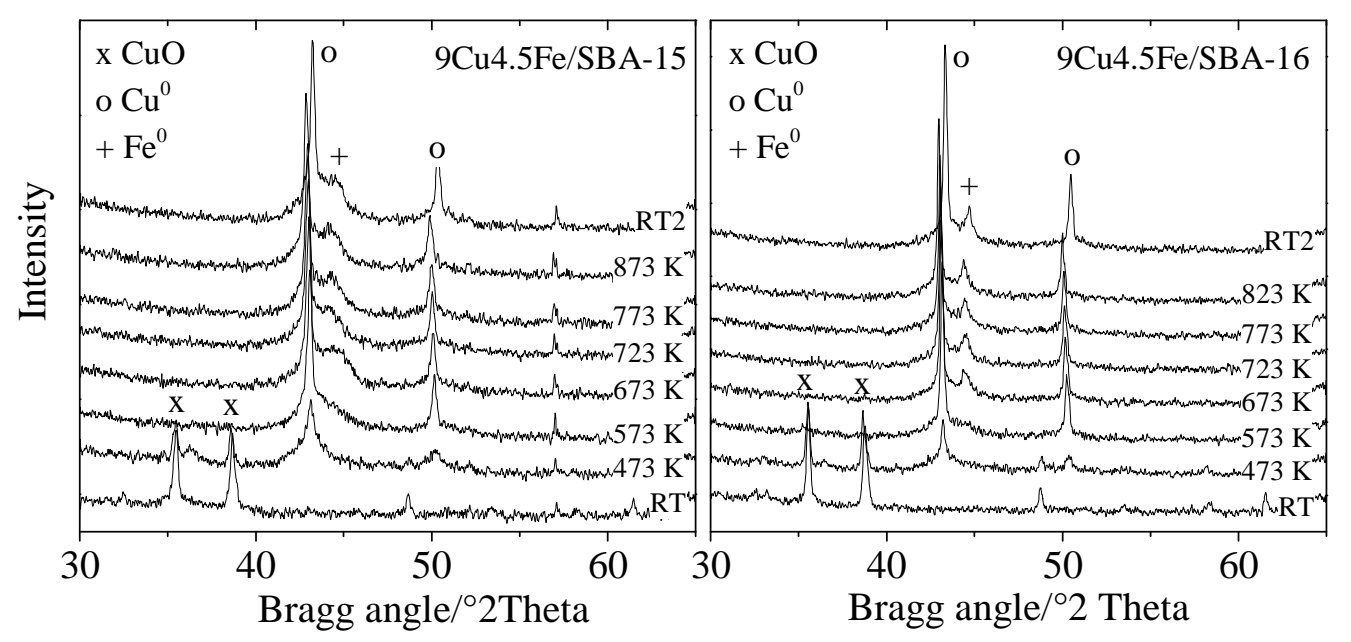

Figure 9. High temperature in situ XRD patterns of 9Cu4.5Fe/SBA-15 and SBA-16 samples reduced at $873 \mathrm{~K}$ in $\mathrm{H}_{2}$ 


\subsection{Catalytic activity for toluene oxidation}

These results support our former observations, that ferrite phase can be found in the channels of SBA-15 and their agglomeration during reduction is restricted, whereas bigger metal crystallites can be formed during the reduction of iron oxide particles on the outer surface of SBA-16.

The temperature dependences of catalytic activities in toluene oxidation on the modified SBA-15 and SBA-16 materials are presented in Fig. 10. $\mathrm{CO}_{2}$ is the only registered carbon-containing product in all cases. Prior to the catalytic tests samples were calcined ex situ at $573 \mathrm{~K}$ for $2 \mathrm{~h}$ in air. Comparing the catalytic activities of the copper containing monocomponent SBA-15 and SBA-16 catalysts it can be seen that on SBA-15 support higher conversion can be achieved. It seems that SBA-15 is a more appropriate support for the formation of catalytically active copper oxide species. Our XRD data confirmed that more finely dispersed copper oxide phase is formed on this catalyst. Introduction of the second metal resulted in the shift of conversion curves to lower temperatures. With lower amount of iron also SBA-15 shows higher catalytic activity, whereas this advantage of the support structure disappears with the addition of higher amount of iron. With 4.5 $\%$ iron content about $5 \%$ lower conversion can be achieved. The mechanism of oxidation [39] supposes that the adsorption of VOCs molecules on the catalyst surface is the essential step of catalytic transformation. The activity in total oxidation of aromatic hydrocarbons is connected with the interaction of the electrons in the aromatic ring with metal oxide species increasing the possibility of electrophyllic attack of adsorbed oxygen and combustion of toluene molecules. The predominant formation of oligomeric $\mathrm{Cu}-\mathrm{O}-\mathrm{Cu}$ and $\mathrm{Fe}-\mathrm{O}-\mathrm{Fe}$ species and very finely dispersed oxide phase providing easier oxygen release and also the easier accessibility of active sites in the wide and straight channels of SBA-15 materials can be an explanation for the higher catalytic activity of these catalysts. The change of catalytic activity in dependence of time on stream at 653 $\mathrm{K}$ is presented in Fig. 11. The high catalytic activity of monocomponent copper catalysts at the beginning of the reaction is followed by a well-defined deactivation, more pronounced for SBA-16 sample. Our XRD results confirm that higher amount of separate $\mathrm{CuO}$ phase can be found in SBA16 sample, so its agglomeration during catalytic reaction can be the explanation for the fast deactivation of this sample. According to UV-Vis data copper can be found in SBA-15 catalyst in the form of isolated copper ions, oligomeric $\mathrm{Cu}-\mathrm{O}-\mathrm{Cu}$ species in the channels, and also as a separate $\mathrm{CuO}$ and $\mathrm{CuFe}_{2} \mathrm{O}_{4}$ spinel phase on the outer surface. Whereas, on SBA-16 support only isolated copper ions and separate copper oxide phase are formed. The presence of oligomeric $\mathrm{Cu}-$ $\mathrm{O}-\mathrm{Cu}$ species is more favorable from the point of oxygen release ability. Additionally, higher amount of finely dispersed copper oxide phase is formed in the channels of SBA-15 in contrast to SBA-16 support, where the copper oxide phase can be found mainly on the outer surface of the silica particles. Addition of iron resulted in a more stable catalytic behavior for both supports and for both iron concentrations. This can be explained by the formation of the mixed CuFe oxide, e.g. ferrite phase, which is in good accordance with the appearance of a $\mathrm{CuFe}$ alloy upon reduction evidenced by Mössbauer spectroscopy. The simultaneous presence of $\mathrm{Cu}^{2+} / \mathrm{Fe}^{3+}$ pairs in the catalysts leads to higher catalytic activity for all bicomponent samples due to the easier oxygen release, according to Mars-van Krevelen mechanism [10, 39]. 


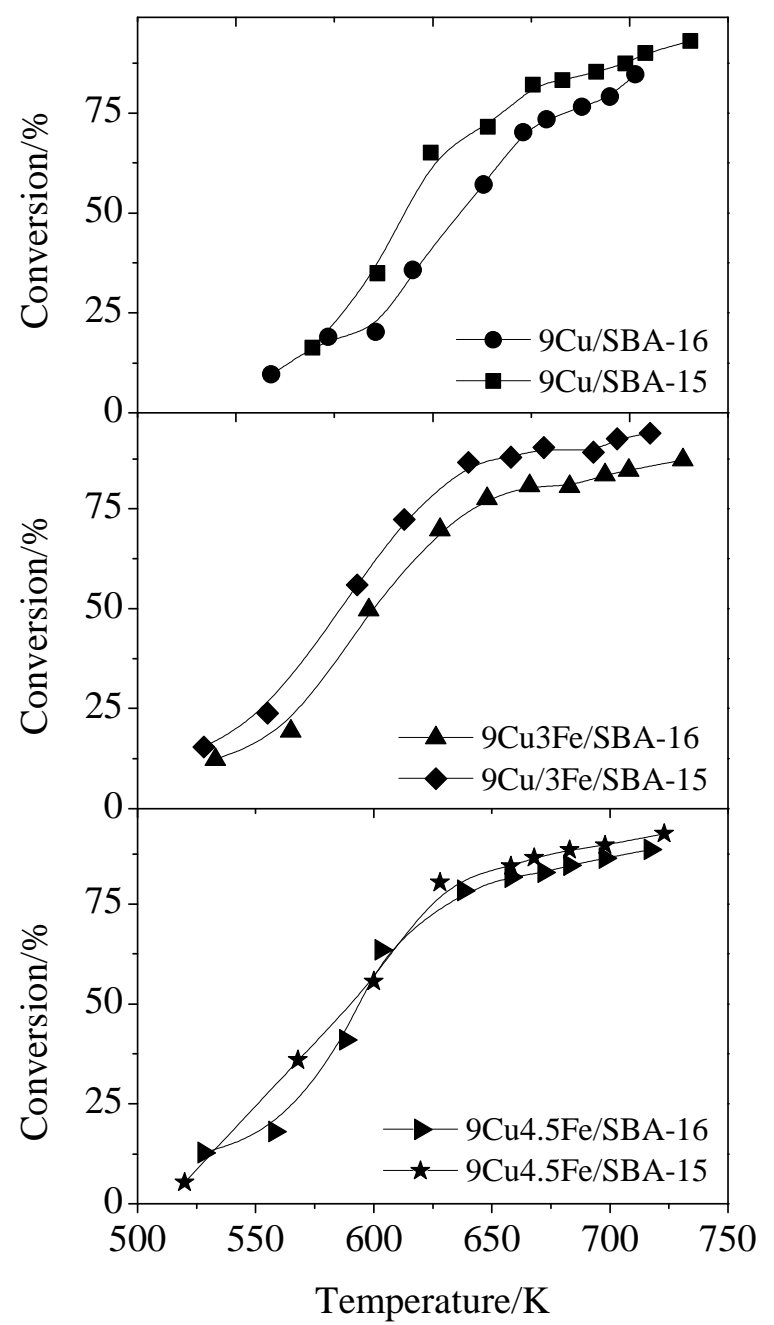

Figure 10. Toluene conversion vs. reaction temperature on the studied samples
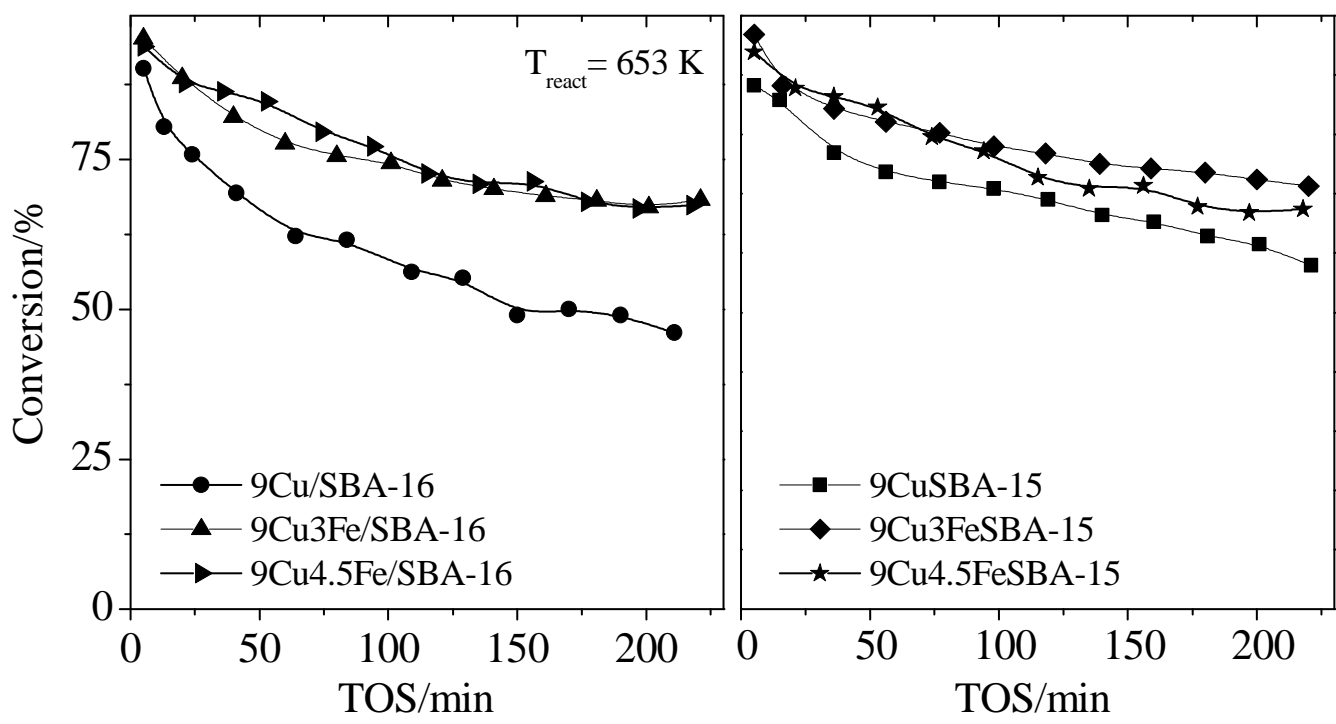

Figure 11. Toluene conversion vs. time on stream on the studied samples 


\section{CONCLUSION}

It was found that SBA-15 and SBA-16 are suitable supports for the preparation of copper and iron containing catalysts, possessing high activity in total toluene oxidation. The variation of the pore structure of the support has a notable influence on the nature and dispersion of the formed metal oxide species as well as on their catalytic activity. It was found that during the impregnation process metal salt can penetrate into the channels of SBA-15 support and finely dispersed copperoxide and copper ferrite phases are formed. These species are more active in toluene oxidation and can resist to agglomeration during the catalytic test. However, on SBA-16 support penetration of impregnating salts is hindered due to its bimodal pore structure and copper and iron oxides can be found on the outer surface of the support as separate phases. In this case the stabilizing effect of the second metal (iron) is also restricted. A more appropriate impregnation procedure can improve the homogeneous dispersion of the metal salts on this support. It was also found that bi-component systems possess higher catalytic activity. The addition of iron resulted in a more stable catalytic behavior for both supports and for both iron concentrations. This result is related with the formation of bimetallic oxide phases, more pronounced on SBA-15 catalyst appearing as a copper ferrite phase.

Acknowledgements Financial support by the Bulgarian-Hungarian Inter-academic Exchange Agreement is greatly acknowledged.

\section{References}

[1] A. Taguchi, F. Schüth, Micropor. Mesopor. Mater. 77 (2005) 1-45.

[2] Ch.-H. Wang, Sh.-Sh. Lin, Ch.-L. Chen, H.-Sh. Weng, Chemosphere 64 (2006) 503-509.

[3] A. Taguchi, F. Schüth, , Micropor. Mesopor. Mater. 77 (2005) 1-45.

[4] M.A. Centeno, M. Paulis, M. Montes, J.A. Odriozola, Appl. Catal. A 234 (2002) 65-78.

[5] N. Novak Tusar, A. Ristic, G. Mali, M. Mazaj, I. Arcon, D. Arcon, V. Kaucic, N. Zabukovec Logar, Chemistry - A European Journal, 16 (2010), 5783-5793.

[6] L. Wang, M. Sakurai, H. Kameyama, J. Hazard. Mater. 154 (2008) 390-395.

[7] T. Masui, H. Imadzu, N. Matsuyama, N. Imanaka, J. Hazard. Mater. 176 (2010) 1106-1109.

[8] L.A. Palacio, E.R. Silva, R. Catalão, J.M. Silva, D.A. Hoyos, F.R. Ribeiro, M.F. Ribeiro, J. Hazard. Mater. 153 (2008) 628-634.

[9] S. Ch. Kim, W.G. Shim, J. Hazar. Mater. 154 (2007) 310-316.

[10] M. Popova, A. Szegedi, Z. Cherkezova-Zheleva, A. Dimitrova, I. Mitov, Appl. Catal. A: General 381 (2010) 26-35.

[11] Á. Szegedi, M. Popova, Ch. Minchev, J. Por. Mater. 17 (2010) 663-668.

[12] M. Popova, Á. Szegedi, Z. Cherkezova-Zheleva, I. Mitov, N. Kostova, T. Tsoncheva, J. Hazard. Mater. 168(1) (2009) 226-232.

[13] A. Szegedi, M. Popova, A. Dimitrova, Z. Cherkezova-Zheleva, I. Mitov, Micropor. Mesopor. Mater. 136 (2010) 106-114.

[14] N. Novak Tusar, S. Jank, R. Glaser, Chem. Cat.Chem., 3 (2011) 254-269.

[15] N. Novak Tusar, A. Ristic, G. Mali, M. Mazaj, I. Arcon, D. Arcon, V. Kaucic, N. Zabukovec Logar, Chemistry - A European Journal, 16 (2010), 5783-5793.

[16] R.S. Araujo, D.C.S. Azevedo, E. Rodriguez-Castellon, A. Jimenez-Lopez, C.L. Cavalcante Jr., J. Mol. Catal. 281 (2008) 154-163.

[17] S. Ordóñez, L. Bello, H. Sastre, R. Rosal, F. V. Díez, Appl. Catal. B 38 (2002) 139-149.

[18] P. Papaefthimiou, Th. Ioannides, X. E. Verykios, Appl. Catal. B: Environ. 13 (1997) 175184.

[19] C.C. Rodrigues, Catal. Comm. 8 (2007) 1227-1231. 
[20] M. Mesa, L. Sierra, J. Patarin, J.-L. Guth, Solid State Science, 7 (2005) 990-997.

[21] D. Carta, A. Corrias, G. Navarra, J. Non-Cryst. Solids, 357 (2011) 2611-2614.

[22] A. A. dos Santos, K. M. Lima, R. T. Figueiredo, S. M. da S. Egues, A. L. D. Ramos, Catal. Lett. 114 (2007) 59-63.

[23] R.S.G. Ferreira, P.G.P. de Oliveira, F.B. Noronha, Appl. Catal. B 29 (2001) 275-283.

[24] S. Ch. Kim, J. Hazard. Mater. 91( 1-3) (2002) 285-299.

[25] H.L. Tidahy, S. Siffert, F. Wyrwalski, J.-F. Lamonier, A. Aboukais, Catalysis Today 119 (2007) 317-320.

[26] S. Minico, S. Scire, C. Crisafulli, R. Maggiore, S. Galvagno, Appl. Catal. B 28 (2000) 245251.

[27] Ch. He, P. Li, H. Wang, J. Cheng, X. Zhang, Y. Wang, Zh. H, J. Hazard. Mater. 181 (1-3) (2010) 996-1003.

[28] J.-L. Cao, Y. Wang, X.-L. Yu, S.-R. Wang, S.-H. Wu, Z.-Y. Yaun, Appl. Catal. B 79 (2008) 26-234.

[29] M. Scariot, S.P. Francisco, M. Jordao, D. Zanchet, M. Logli, V.P. Vicentini, Catal. Today 133-135 (2008) 174-180.

[30] W.M. Shaheen, Mater. Chem. Phys. 101 (2007) 182-190.

[31] B.N.T. Nguyen, C.A. Leclerc, J. Power Sources 163 (2007) 623-629.

[32] H. G. El-Shobaky, Y.M. Fahmy, Mater. Res. Bull. 41 (2006) 1701-1713.

[33] G. Litt, C. Almquist, Appl. Catal. B: Environmental 90 (2009) 10-17.

[34] D. Zhao, J. Feng, Q. Huo, N. Melosh, G.H. Fredrickson, B.F. Chmelka, G.D. Stucky, Science 279 (1998) 548-552.

[35] M. Popova, A. Szegedi, K. Lazar, Z. Karoly, Micropor. Mesopor. Mater. 151 (2012) 180187.

[36] A. Szegedi, G. Pál-Borbély, K. Lázár, React. Kinet. Catal. Lett. 74 (2001) 277-287.

[37] W. Kündig, H. Bömmel, G. Constabaris, H. Lindquist, Phys. Rev., 142 (1966) 327-333.

[38] S. Roy, J. Ghose, J. Magn. Magn. Mater., 307 (2006) 32-37.

[39] S.H. Taylor, C. S. Heneghan, G. J. Hutchings, I. D. Hudson, Catal. Today 59 (2000) 249259. 